\title{
Effects of Nitric Acid Activation on Textural, Surface, and Supercapacitive Properties of Ultra-Small Carbon Nanospheres
}

\author{
Zhe Chen ${ }^{a}$ and Zhibin Ye ${ }^{*, a, b}$ \\ ${ }^{a}$ Bharti School of Engineering, Laurentian University, Sudbury, Ontario P3E 2C6, Canada \\ ${ }^{b}$ Department of Chemical and Materials Engineering, Concordia University, Montreal, \\ Quebec H3G 1M8, Canada \\ Email: zhibin.ye@concordia.ca (Z. Y.)
}

\begin{abstract}
Chemical activation of carbon materials is critical to modify their textural and surface properties in an effort to optimize their supercapacitive performance as electrode materials for supercapacitors. This present work investigates the effects of nitric acid activation on the textural, surface, and supercapacitive properties of ultra-small carbon nanospheres with a uniform size of $24 \mathrm{~nm}$ synthesized through a unique catalytic emulsion polymerization strategy. Nitric acid activation has been undertaken at different temperatures for various time. The effects of these two activation parameters have been systematically examined, with some important correlations established. The optimum activation conditions for achieving the best supercapacitive performance in different aqueous electrolytes have been identified.
\end{abstract}

Keywords carbon nanospheres, chemical activation, nitric acid, supercapacitors

\section{Introduction}

Porous carbon-based supercapacitors have received enormous research attention in recent years due to their valuable properties for energy storage, such as fast charging-discharging, high power density, and ultra-long cyclic stability compared to batteries. ${ }^{[1]}$ However, carbon-based supercapacitors still face the challenges of low energy density and poor rate performance at high currents, restricting their broader applications. While tuning textural properties of the porous carbons (such as surface area, pore length, and pore size distribution) is a common way to improve their supercapacitive properties, surface functionalization of carbon materials with functional groups containing foreign atoms such as oxygen, nitrogen, boron, and phosphorous can also efficiently improve their supercapacitive performances. ${ }^{[2]}$ Methods to introduce foreign atoms to carbon materials include chemical oxidation, electrochemical oxidation, cold plasma treatment, and gaseous oxidation. Among them, chemical oxidation is most common to improve the supercapacitive performance by enhancing energy and power densities. ${ }^{[3]}$

Commonly used chemical oxidation agents include nitric acid, sulfuric acid, potassium hydroxide, etc. In particular, nitric acid is often used as a strong oxidant to introduce some functional groups to the surface of carbon materials. ${ }^{[4]}$ These groups can improve the wettability of the electrode materials to enhance the utilization of the surface area and can also provide pseudocapacitive properties caused by redox reactions of carbonyl-type surface oxygen groups. These changes may also affect the specific surface area and pore structure of the carbon materials, and lead to a notable improvement of the specific capacitance and the cyclic performance. ${ }^{[5]}$ Nitric acid activation is usually conducted at a moderate temperature $\left(25-80{ }^{\circ} \mathrm{C}\right)$, and easily introduces oxygen functional groups, albeit sometimes at the sacrifice of the morphology and textural characteristics of the carbon materials.
A large variety of carbon materials obtained from different precursors/strategies have thus far been investigated for nitric acid activation, with significant improvements in specific capacitance yielded. These include char- and biowaste-derived carbon materials, ${ }^{[5-7]}$ ordered mesoporous/macroporous carbons by both hard and soft templating, ${ }^{[8-15]}$ graphene, ${ }^{[16]}$ calcium carbide derived carbon, ${ }^{[17]}$ and carbon spheres. ${ }^{[18]}$

Our group has recently developed a catalytic emulsion polymerization technique for the convenient, tailored synthesis of ultra-small carbon nanospheres (CNSs) with uniform, tunable ultra-small sizes within $10-50 \mathrm{~nm} .{ }^{[19]}$ In this technique, tightly cross-linked polymer nanospheres of 1,3-diethynylbenzene (DEB) were firstly produced via catalytic emulsion polymerization. The polymer nanospheres were carbonized to render well-defined carbon nanospheres. Activated CNSs obtained by $\mathrm{KOH}$ activation showed superior supercapacitive performance with high specific capacitance and high rate performance at high currents. ${ }^{[19]}$ Nevertheless, the as-produced CNSs without undergoing activation are featured with restricted hydrophobic surface area $\left(550 \mathrm{~m}^{2} \cdot \mathrm{g}^{-1}\right)$, though having some micropores, and thus limited supercapacitance. Different from our previous study, to improve their supercapacitive performance, the CNSs are herein activated with concentrated nitric acid as the activation agent. A systematic study on the effects of activation parameters on the textural/surface properties and supercapacitive performance of the resulting nitric acid activated CNSs in different electrolytes has been undertaken. The correlations between the acidic activation and supercapacitive performance of this range of CNSs provide important guidelines for their proper usage as electrode materials in supercapacitors.

\section{Experimental}

\section{Materials}

Chemicals, including 1,3-diethynylbenzene (DEB, 97\%, Al- 


\section{Report}

drich), sodium dodecyl sulphate ( $\geq 98.5 \%$, Aldrich), palladium acetate $\left(98 \%\right.$, Strem Chemicals), $\alpha, \alpha^{\prime}$-bis(di-tert-butylphosphino)-o-xylene (97\%, Strem Chemicals), methanol (ACS reagent, Fisher Scientific), methanesulfonic acid (99.5\%, Aldrich), dichloromethane (HPLC grade, Aldrich), nitric acid (69.3 wt\%, Fisher Scientific), sulfuric acid (96.9 wt\%, Fisher Scientific), potassium hydroxide (reagent grade, 90\%, flakes, Aldrich), titanium foil (99.95\%, Aldrich), nafion solution (5 wt \% in lower aliphatic alcohols, Aldrich), platinum wire $(0.5 \mathrm{~mm}$ in diameter, 99.95\%, Strem Chemicals), and conducting carbon (acetylene black $100 \%$, Soltex) were used as received without any additional purification. Deionized (DI) water was purified by a Barnstead-Synbron Nanopure II purification system.

\section{Synthesis of CNS from polyDEB polymer nanospheres by catalytic emulsion polymerization}

Cross-linked polyDEB nanospheres of a size of $24 \mathrm{~nm}$ were prepared by Pd-catalyzed emulsion polymerization, followed with a subsequent hydrothermal treatment. A typical procedure is as follows. Sodium dodecyl sulfate $(0.8 \mathrm{~g})$ was dissolved in deionized water $(15.6 \mathrm{~g})$ in a round-bottom Schlenk flask. DEB $(1.86 \mathrm{~g}, 14.74 \mathrm{mmol})$ was then added under nitrogen protection. The solution was sonicated for $15 \mathrm{~min}$ and was vigorously stirred in a water bath set at $60^{\circ} \mathrm{C}$ for $5 \mathrm{~h}$ to achieve a stable emulsion. In the meantime, palladium acetate $(3.31 \mathrm{mg}, 14.74$ $\mu \mathrm{mol})$ and $\alpha, \alpha^{\prime}$-bis(di-t-butylphosphino)-o-xylene (17.45 mg, $44.40 \mu \mathrm{mol}$ ) were dissolved in a mixed solvent containing 0.54 $\mathrm{mL}$ of dichloromethane and $0.06 \mathrm{~mL}$ of methanol in a small vial. The mixture was sonicated at room temperature for $10 \mathrm{~min}$ until all the solids were dissolved. The catalyst mixture was then injected into the polymerization flask under stirring at $450 \mathrm{rpm}$ and $60{ }^{\circ} \mathrm{C}$, followed with the addition of three drops of methanesulfonic acid to generate catalytically active cationic $\mathrm{Pd}$ species to start the polymerization. The emulsion polymerization lasted overnight, rendering a dark brown emulsion dispersion.

The resulting emulsion was diluted in DI water, and placed into an autoclave for hydrothermal treatment. In the hydrothermal treatment, the autoclave containing the mixture was heated to $220^{\circ} \mathrm{C}$ in an oven overnight (about $15 \mathrm{~h}$ ) and was then allowed to cool down to room temperature naturally. The resulting hydrothermally treated polymer was collected by filtration, washed with a large amount of deionized water, and then dried under vacuum at $60^{\circ} \mathrm{C}$ for $48 \mathrm{~h}$.

The CNS sample was obtained by carbonizing the hydrothermally treated polymer nanospheres in a tube furnace to $800^{\circ} \mathrm{C}$ at a heating rate of $10^{\circ} \mathrm{C} \cdot \mathrm{min}^{-1}$ in a $\mathrm{N}_{2}$ atmosphere and held at $800^{\circ} \mathrm{C}$ for $1 \mathrm{~h}$.

\section{Nitric acid activation of CNS}

In a typical activation process, $100 \mathrm{mg}$ of CNS was dispersed in $10 \mathrm{~mL}$ of concentrated nitric acid (69.3 wt\%) and was stirred with a magnetic stirrer (at $450 \mathrm{rpm}$ ) in a preheated oil bath set at a prescribed temperature. Several nitric acid-activated CNS samples were prepared by varying the temperature $\left(25,50,80\right.$, or $\left.100^{\circ} \mathrm{C}\right)$ and activation time $(2$ or $4 \mathrm{~h})$. The activated products were washed with a large amount of deionized water until a $\mathrm{pH}$ of $\sim 7$ was reached, further washing three times with ethanol, the product was finally dried under vacuum. Nitric acid activated CNS samples were termed correspondingly as A-CNS- $x$ Cyh with prefix A-CNS noting activated carbons, $x$ noting nitric acid activation temperature (in ${ }^{\circ} \mathrm{C}$ ), and $y$ noting activation time (in h).

\section{Characterizations and measurements}

The polymer emulsion obtained following the catalytic emulsion polymerization was characterized with a Malvern Instruments Nanosizer S90 dynamic light scattering (DLS) instrument for the size distribution of polymer nanospheres. Transmission electron microscopy (TEM) measurements of the polymer and carbon nanospheres were taken on a JEOL 2010F field emission electron microscope operated at $200 \mathrm{keV}$. Fourier-transform infrared (FTIR) spectroscopic characterization of the A-CNS samples was performed on a Thermo Scientific Nicolet 6700 Analytical FTIR spectrometer. Thermogravimetric analysis (TGA) of the A-CNS samples was carried out on a TA Instruments Q50 TGA. Measurements were performed in a nitrogen atmosphere. The samples were first heated to $100^{\circ} \mathrm{C}$ at a rate of $10^{\circ} \mathrm{C} \cdot \mathrm{min}^{-1}$, held at $100^{\circ} \mathrm{C}$ for $10 \mathrm{~min}$, and then heated to $800^{\circ} \mathrm{C}$ at a heating rate of $10^{\circ} \mathrm{C} \cdot \mathrm{min}^{-1}$.

The surface area, pore volume, and pore size distribution of the carbon samples were measured using a Micromeritics ASAP 2020 physiosorption analyzer by $\mathrm{N}_{2}$ sorption at $77 \mathrm{~K}$. The specific surface area was calculated from the Braunauermmett-Teller (BET) method. Non-local density function theory (NLDFT) model was used to obtain both micropore size distribution and mesopore/macropore size distribution from $\mathrm{N}_{2}$ desorption. All carbon samples were degassed at $200^{\circ} \mathrm{C}$ for $30 \mathrm{~h}$ before each sorption analysis.

Electrochemical measurements, including cyclic voltammetry (CV), galvanostatic charge/discharge (GCD), and electrochemical impedance spectroscopy (EIS) were performed on a Metrohm Autolab PGSTAT100 electrochemical instrument in both 2 and 3-electrode cells. In 3-electrode tests, a coiled platinum wire was used as the counter electrode and a saturated calomel electrode (SCE) was used as the reference electrode, with $2 \mathrm{M} \mathrm{KOH}$ or $1 \mathrm{M} \mathrm{H}_{2} \mathrm{SO}_{4}$ aqueous solution as the electrolyte.

For electrochemical testing in $\mathrm{KOH}$, working electrodes were prepared with nickel foam $\left(1 \mathrm{~cm}^{2}\right)$ as the current collector. To prepare the electrode, the carbon sample (80 wt\%), conducting carbon (10 wt\%), and Nafion (10 wt\%) were dispersed in ethanol under sonication in a small vial. The dispersion was evenly coated on two pieces of nickel foam by drop casting. Subsequently, both pieces of nickel foam were dried in an oven at $100{ }^{\circ} \mathrm{C}$ for ca. $2 \mathrm{~h}$ and pressed together under 2 tons of pressure to a thickness of $\sim 0.5 \mathrm{~mm}$. The loading of active material on each electrode is about $2.5 \mathrm{mg}$ at a density of 2.5 $\mathrm{mg} \cdot \mathrm{cm}^{-2}$. The electrode was then soaked in $\mathrm{KOH}$ electrolyte for $4 \mathrm{~h}$ under vacuum. CV curves were obtained between -1 and 0 $\mathrm{V}$ (vs. SCE) at different scan rates $(200,100,50,25,10,5$ $\mathrm{mV} \cdot \mathrm{s}^{-1}$, respectively). GCD measurements were performed at current densities of $30,20,10,5,3,2,1$ and $0.5 \mathrm{~A} \cdot \mathrm{g}^{-1}$, respectively, within -1 and $0 \mathrm{~V}$ (vs. SCE). EIS measurements were conducted at the open circuit potential between $0.01 \mathrm{~Hz}$ and 10 $\mathrm{kHz}$ with an $\mathrm{AC}$ perturbation of $10 \mathrm{mV}$.

The specific capacitance $\left(\mathrm{C}_{\mathrm{sp}}\right.$ in $\left.\mathrm{F} \cdot \mathrm{g}^{-1}\right)$ was calculated from the $\mathrm{CV}$ curves through the following equation: $:^{[19,20]}$

$$
C_{\mathrm{sp}}=\frac{\frac{1}{2} \int i \mathrm{~d} V}{m \Delta V v}
$$

where $i$ and $V$ are the current and voltage, respectively, in the CV curves, $\int i \mathrm{~d} V$ is the integration of the current loop over the whole voltage range, $m$ is the mass of the active carbon, and $v$ is the scan rate. The specific capacitance was also calculated from the GCD discharge curve through the following equation: $:^{[19,20]}$

$$
C_{\mathrm{sp}}=\frac{i}{m \mathrm{~d} V / \mathrm{d} t}
$$




\section{General Chemistry}

where $i$ is the discharge current, $m$ is carbon mass, and $\mathrm{d} V / \mathrm{d} t$ is calculated as the slope of the discharge curve within the voltage range following the end of Ohmic drop to the end of the discharge curve. In all CV and GCD measurements, the cell was cycled until negligible changes were observed (ca. 10 cycles) prior to recording the data for calculation. The measurements in $1 \mathrm{M} \mathrm{H}_{2} \mathrm{SO}_{4}$ electrolyte were done similarly except within the voltage window of -0.2 and $0.8 \mathrm{~V}$.

A symmetric 2-electrode cell was also prepared with A-CNS-80C4h as the active carbon. The two electrodes, prepared on nickel foam in the same manner as in the 3-electrode test, were separated with a filtration paper soaked in $2 \mathrm{M} \mathrm{KOH}$. CV, GCD, and EIS measurements were performed in the voltage range of $0-1 \mathrm{~V}$. The specific capacitance was calculated from CV and GCD data according to Equations 2.3 and 2.4, respectively:

$$
\begin{gathered}
C_{\mathrm{sp}}=\frac{\int i \mathrm{~d} V}{m \Delta V v} \\
C_{\mathrm{sp}}=\frac{2 i}{m \mathrm{~d} V / \mathrm{d} t}
\end{gathered}
$$

where $i$ is the current, $V$ is voltage, $\int i \mathrm{~d} V$ is the integration of the current loop over $0-1 \mathrm{~V}, m$ is the mass of the active carbon material in each electrode, $v$ is the rate of voltage scan and $\mathrm{dV} / \mathrm{d} t$ is calculated as the discharge slope within the voltage range from the end of ohmic drop to the end of the discharge curve.

\section{Results and Discussion}

\section{Synthesis and characterization of CNS}

The CNS studied herein is obtained by convenient carbonization of highly cross-linked polyDEB nanospheres as the polymer precursor. The polymer nanospheres are synthesized by direct $\mathrm{Pd}$-catalyzed emulsion polymerization of $\mathrm{DEB}$ as a difunctional acetylenic monomer. ${ }^{[19]}$ This unique method for synthesis of CNSs was firstly developed by our research group. For the emulsion polymerization, DEB is firstly emulsified (with the use of an anionic surfactant, SDS) in a continuous phase of water to form oil-in-water emulsion. The subsequent addition of a diphosphine-ligated $\mathrm{Pd}(\mathrm{II})$ catalyst system renders effectively the cross-linked polyDEB nanospheres stabilized by SDS. ${ }^{[19]}$ During the polymerization, DEB is incorporated through one of its two alkyne groups, rendering a pendant alkyne group that can be subsequently enchained to render a cross-linked structure. ${ }^{[1,22]}$ DLS characterization was undertaken on the resulting polymer emulsion to determine the average particle size and particle size distribution of the polymer nanospheres. Figure 1a illustrates the particle size distribution, which shows a single narrow peak with Z-average size of ca. $24 \mathrm{~nm}$ and the polydispersity index (PDI) of 0.074. Such a low PDI suggests that the polymer nanospheres have very uniform sphere size and are well dispersed in water.

Subsequently, the resulting polymer nanosphere sample was hydrothermally treated at $220^{\circ} \mathrm{C}$ and then carbonized under $\mathrm{N}_{2}$ to render CNS. During the hydrothermal treatment, surfactant SDS degrades and polymer nanoparticles aggregate together to generate hierarchical intersphere mesopores and macropores. ${ }^{[19]}$ The originally clear emulsion became cloudy with the presence of visible big particles with sizes in the millimeter scale. The FTIR spectra of the polymer samples before and after hydrothermal treatments are shown in Figure 1b. Five characteristic bands (1591, 2107, 2856, 2926, and $3295 \mathrm{~cm}^{-1}$ ) are observed in the spectra. In particular, peaks found at 3295 and $2107 \mathrm{~cm}^{-1}$ correspond to $v_{\mathrm{c} \equiv \mathrm{C}-\mathrm{H}}$ band and $v_{\mathrm{C} \equiv \mathrm{C}}$ bands of the pendent, unreacted triple bonds. Those around $1591 \mathrm{~cm}^{-1}$ are characteristic of the stretching vibrations of the conjugated double bonds, and peaks at 2856 and $2926 \mathrm{~cm}^{-1}$ indicate the presence of $\mathrm{C}-\mathrm{H}$ single band. ${ }^{[22]}$ In the hydrothermally treated sample, the triple bond peaks disappear completely, indicating the degradation and/or further cross-linking reaction of the pendant triple bonds during the hydrothermal treatment.
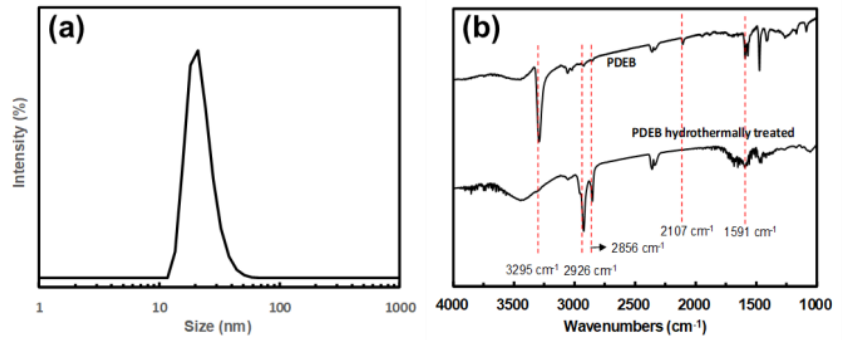

Figure 1 (a) DLS size distribution of the polymer nanospheres in the as-produced emulsion; (b) FTIR spectra of as produced PDEB nanospheres and the hydrothermally treated sample.

The direct carbonization of the hydrothermally-treated polymer nanosphere sample at $800^{\circ} \mathrm{C}$ for $1 \mathrm{~h}$ under $\mathrm{N}_{2}$ protection renders the CNS sample. A TEM image of the unactivated CNS is shown in Figure 2a. Uniform nanospheres with an average sphere size of about $24 \mathrm{~nm}$ are observed, which is in good agreement with the DLS size found above for the polymer nanospheres. The mesopores and macropores resulting from packing/aggregation of the nanospheres are also clearly seen. $\mathrm{N}_{2}$ sorption isotherm and mesopore/macropore size distribution curve for the CNS sample are shown in Figures $2 \mathrm{~b}$ and 2c, respectively. Figure $2 \mathrm{~b}$ shows a type IV isotherm, with a slight uptake in the low relative pressure range $\left(P / P_{0}<0.1\right)$ and a
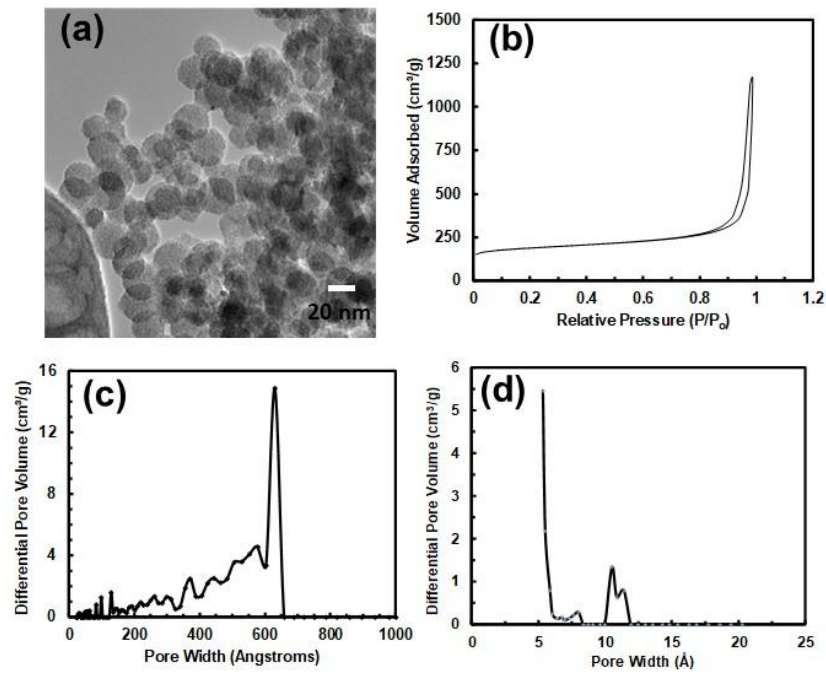

Figure 2 (a) TEM image; (b) $\mathrm{N}_{2}$ sorption isotherm, (c) mesopore size distribution (determined with NLDFT model), and (d) micropore size distribution (determined with NLDFT model) of CNS. 
Table 1 Results from $\mathrm{N}_{2}$ sorption and contact angle measurements

\begin{tabular}{|c|c|c|c|c|c|c|c|c|c|c|c|}
\hline \multirow{2}{*}{$\begin{array}{l}\text { Carbon } \\
\text { Sample }\end{array}$} & \multicolumn{3}{|c|}{$\begin{array}{l}\text { Surface Area } / \\
\qquad\left(\mathrm{m}^{2} \cdot \mathrm{g}^{-1}\right)\end{array}$} & \multicolumn{3}{|c|}{$\begin{array}{l}\text { Pore Volume } \\
\qquad\left(\mathrm{cm}^{3} \cdot \mathrm{g}^{-1}\right)\end{array}$} & \multicolumn{2}{|c|}{$\begin{array}{c}\text { Average } \\
\text { Pore Size / } \\
(\AA)\end{array}$} & \multicolumn{3}{|c|}{$\begin{array}{c}\text { Contact Angle/ } \\
\left({ }^{\circ}\right)\end{array}$} \\
\hline & $S_{\mathrm{BET}}$ & $S_{d>20 \AA}$ & $\% S_{d>20 \AA}$ & $V_{\text {total }}$ & $V_{\mathrm{d}>20 \AA}$ & $\% V_{d>20 \AA}$ & $d_{\text {meso }}$ & $d_{\text {micro }}$ & Water & $\begin{array}{c}1 \mathrm{M} \\
\mathrm{H}_{2} \mathrm{SO}_{4}\end{array}$ & $2 \mathrm{M} \mathrm{KOH}$ \\
\hline CNS & 591 & 252 & $43 \%$ & 1.81 & 1.66 & 92 & 429 & 6.8 & 134 & 116 & 119 \\
\hline A-CNS25C2h & 493 & 243 & $49 \%$ & 1.81 & 1.70 & 94 & 425 & 8.1 & & & \\
\hline A-CNS25C4h & 482 & 244 & $51 \%$ & 1.94 & 1.83 & 94 & 426 & 8.3 & 133 & 116 & 119 \\
\hline A-CNS50C2h & 487 & 235 & $48 \%$ & 1.67 & 1.55 & 93 & 430 & 7.0 & & & \\
\hline A-CNS50C4h & 512 & 238 & $46 \%$ & 2.00 & 1.88 & 94 & 417 & 8.0 & 118 & 114 & 109 \\
\hline A-CNS80C2h & 470 & 230 & $49 \%$ & 1.59 & 1.48 & 93 & 400 & 8.2 & & & \\
\hline A-CNS80C4h & 532 & 238 & $45 \%$ & 2.00 & 1.87 & 94 & 429 & 7.7 & 102 & 125 & 97 \\
\hline $\mathrm{A}-\mathrm{CNS} 100 \mathrm{C} 2 \mathrm{~h}$ & 596 & 275 & $46 \%$ & 2.00 & 1.86 & 93 & 432 & n.d. & & & \\
\hline A-CNS100C4h & 0.23 & & & 0 & & & & & & & \\
\hline
\end{tabular}

${ }^{a}$ Surface area of mesopores/macropores $\left(S_{d>20 \AA}\right)$ determined with $t$-plot method. The percentage data denote the percentage of surface area of mesopores relative to the total surface area. ${ }^{b}$ Total pore volume $\left(V_{\text {total }}\right)$, mesopore/macropore volume $\left(V_{d>20} \AA\right)$ determined with $t$-plot method. The percentage data denote the percentage of mesopore/macropore volume relative to the total pore volume. ${ }^{c}$ Average mesopore/macropore size $\left(d_{\text {meso }}\right)$ determined from the $\mathrm{N}_{2}$ desorption data with NLDFT model. Average micropore size ( $\left.d_{\text {micro }}\right)$ determined with NLDFT model.

sharp intense uptake at the high relative pressure end $(0.8<$ $\left.P / P_{0}<1\right)$ with a distinct $\mathrm{H} 1$ type hysteresis loop characteristic of the packing/aggregates of uniform spheres in a regular manner. $^{[19]}$ Its specific BET surface area $\left(S_{\text {BET }}\right)$ is $591 \mathrm{~m}^{2} \cdot \mathrm{g}^{-1}$, with $57 \%$ of the surface area originating from micropores. Its total pore volume is high at $1.81 \mathrm{~cm}^{3} \cdot \mathrm{g}^{-1}$ and its micropore volume is, however, low at $0.18 \mathrm{~cm}^{3} \cdot \mathrm{g}^{-1}$ arising from intra-sphere micropores. These $\mathrm{N}_{2}$ sorption results are summarized in Table 1. These data suggest the presence of abundant inter-sphere mesopores/macropores resulting from packing and aggregation of the nanospheres. From Figure 2c, CNS has a broad mesopore/macropore size range primarily from $20 \mathrm{~nm}$ to $63 \mathrm{~nm}$, with the average size of ca. $43 \mathrm{~nm}$. Figure $2 \mathrm{~d}$ shows its micropore size distribution, with the majority of micropores less than $6 \AA$ and a small portion within $10-12 \AA$.

Composed nearly exclusively of carbon, the unactivated CNS sample is highly hydrophobic. From the contact angle measurements on a thin film of CNS coated on carbon-coated aluminum foil as the substrate, the contact angle of DI water, 1 $\mathrm{M} \mathrm{H}_{2} \mathrm{SO}_{4}$ solution, and $2 \mathrm{M} \mathrm{KOH}$ solution on the CNS film is $134^{\circ}, 116^{\circ}$, and $118^{\circ}$, respectively (see Table 1 ). The latter two solutions are commonly employed as the aqueous electrolytes for porous carbon-based supercapacitors. Such a highly hydrophobic nature prevents the sufficient wetting of the surface with the aqueous electrolyte. Along with the low surface area, this feature renders the CNS with poor supercapacitive performance in aqueous electrolytes (such as $\mathrm{KOH}$ and $\mathrm{H}_{2} \mathrm{SO}_{4}$ ) with low specific capacitance even at low current densities as shown below, despite the expected short micropore length arising from its ultra-small nanosphere sizes.

\section{Nitric acid activation of CNS and characterizations}

CNS is activated herein in concentrated nitric acid $(69.3$ wt\%) at various temperature $\left(25-100{ }^{\circ} \mathrm{C}\right)$ for different time $(2$ or $4 \mathrm{~h}$ ). The resulting A-CNS samples have been thoroughly characterized for their spectroscopic feature, and textural/surface properties. The effects of the activation parameters (temperature and time) on these properties have been examined. Figure $\mathrm{S} 1$ in Supporting Information shows the $\mathrm{N}_{2}$ sorption isotherms of the various A-CNS samples (A-CNS25C2h, $\mathrm{A}-\mathrm{CNS} 25 \mathrm{C} 4 \mathrm{~h}, \mathrm{~A}-\mathrm{CNS} 50 \mathrm{C} 2 \mathrm{~h}, \mathrm{~A}-\mathrm{CNS} 50 \mathrm{C} 4 \mathrm{~h}, \mathrm{~A}-\mathrm{CNS} 80 \mathrm{C} 2 \mathrm{~h}$, A-CNS80C4h, A-CNS100C2h), which resemble very well that of the unactivated CNS with the distinct type IV isotherm and $\mathrm{H} 1$ type hysteresis loop. This indicates the very well retained nanosphere structures and textures in the nitric acid-activated samples within the activation condition range (i.e., temperature $\leq 80^{\circ} \mathrm{C}$ and time $\leq 4 \mathrm{~h}$; up to $2 \mathrm{~h}$ at $100^{\circ} \mathrm{C}$ ) despite the surface oxidation. At the highest activation temperature of $100{ }^{\circ} \mathrm{C}$, a complete collapse of the nanosphere structure, however, occurred with negligible $\mathrm{N}_{2}$ sorption observed when the activation time was extended beyond $2 \mathrm{~h}$. This indicates the severe harsh oxidation of the carbon material by nitric acid at $100{ }^{\circ} \mathrm{C}$. The results (surface area, pore volume, average pore size) obtained from the $\mathrm{N}_{2}$ sorption analysis are summarized in Table 1.

The mesopore/macropore and micropore size distributions of the various A-CNS samples are shown in Figures S2 and S3, respectively, in Supporting Information. Except the activated sample at $100{ }^{\circ} \mathrm{C}$ for $4 \mathrm{~h}$ that shows negligible surface area/pore volume, only insignificant marginal changes with the textural parameters are observed at the activation conditions ( $T$ $\leq 80^{\circ} \mathrm{C}$ and $t \leq 4 \mathrm{~h} ; t \leq 2 \mathrm{~h}$ at $100^{\circ} \mathrm{C}$ ). This differs from chemical activation with $\mathrm{KOH}$ as the activation agent, which leads to the significant enhancements in both surface area and pore volume by creating more pore structures. ${ }^{[19,21]}$ Herein, minor decreases in the surface area are instead noticed after nitric acid activation, which possibly result from some minor structural collapse after the activation and/or the occlusion of some micropores due to the generation of surface functionalities. A decrease in surface area was also seen with other carbons following nitric acid activation. $^{[12]}$

Though having only marginal effects on textural properties, nitric acid activation has been found to be highly effective in introducing surface functionalities onto the resulting activated carbons. Spectroscopic characterizations have been undertaken to monitor chemical composition changes on the surface of the carbon samples before and after nitric acid modification. Figure $3 \mathrm{a}$ shows the FTIR spectra of CNS, A-CNS25C4h, A-CNS50C4h, and A-CNS80C4h. A broad peak at around 3432 $\mathrm{cm}^{-1}$ is observed in all the four samples, which is mainly caused by the $\mathrm{O}-\mathrm{H}$ stretching vibration of the adsorbed water. ${ }^{[8]} \mathrm{An}$ other broad band is observed at $1239 \mathrm{~cm}^{-1}$, which should be caused by the stretching vibration of the $\mathrm{C}-\mathrm{O}-\mathrm{C}$ bonds. ${ }^{[8]}$ In addition, the $\mathrm{C}=\mathrm{O}$ stretching vibrations related to carbonyl and/or carboxyl groups can be found at around $1733 \mathrm{~cm}^{-1}$. ${ }^{[8]}$ The spectra of the nitric acid activated samples are similar to that of the unactivated CNS, except with significantly more intense bands at $1733 \mathrm{~cm}^{-1}$ and $1239 \mathrm{~cm}^{-1}$. This indicates the presence of more oxygen-containing functional groups on the surface of the activated samples. Moreover, with the increase of 

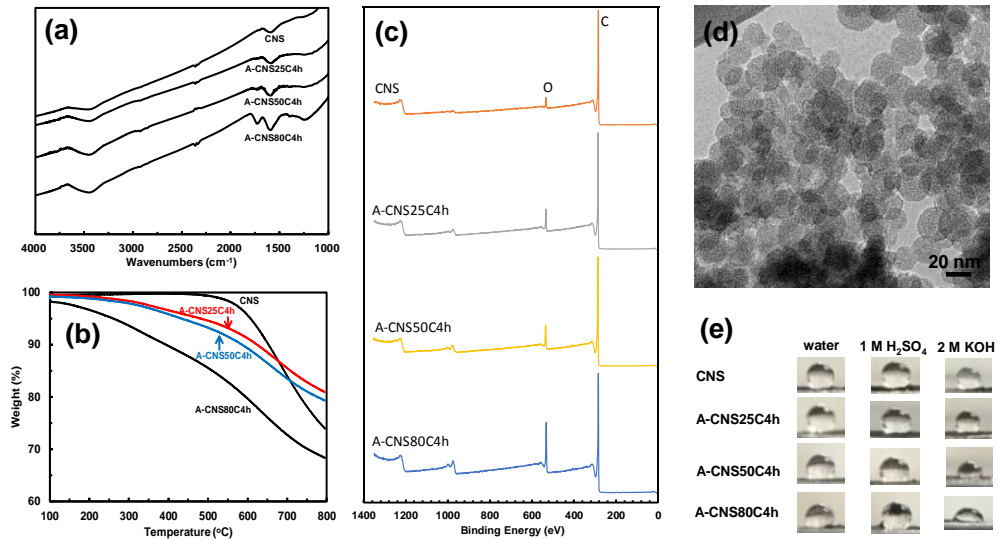

Figure 3 (a) FTIR spectra, (b) TGA thermograms, and (c) XPS survey spectra of unactivated and nitric acid-activated carbon samples; (d) TEM image of A-CNS50C4h; (e) images of droplets of different solutions on thin films of different carbon materials for contact angle determination.

the activation temperature from 25 to $80{ }^{\circ} \mathrm{C}$, the intensity of these two bands increases gradually.

Figure $3 b$ compares TGA curves of unactivated CNS and the three activated samples. The weight loss in TGA can be roughly considered as the amount of surface functional groups present on nitric acid activated samples. ${ }^{[16]}$ For unactivated CNS, there is nearly no weight loss by $500{ }^{\circ} \mathrm{C}$, showing a relatively clean porous carbon surface. For the activated samples, the weight loss at $500{ }^{\circ} \mathrm{C}$ increases with the increasing activation temperature. In particular, the weight loss for A-CNS80C4h at $500{ }^{\circ} \mathrm{C}$ exceeds $15 \%$. The TGA results also confirm the increasing quantity of surface functional groups with the increase of activation temperature. ${ }^{[23]}$

Figure $3 c$ shows the XPS survey spectra of unactivatged CNS and three activated samples, A-CNS25C4h, A-CNS50C4h, and A-CNS80C4h. Carbon and oxygen are the two predominant elements in these carbon samples, with only trace amounts of $\mathrm{N}, \mathrm{P}$, and Pd. Relative to unactivated CNS (oxgen atomic content: $4.4 \%$ ), the three activated samples show enhanced oxygen atomic content $(8.6 \%, 10.0 \%$, and $14.8 \%$, respectively), which increases with the increase of the activation temperature from 25 to $80^{\circ} \mathrm{C}$. This further confirms the increasing quantity of oxygen-containing surface functionalities upon the increase of nitric acid activation temperture. Figure S4 in Supporting Information shows the $C_{1 s}$ and $\mathrm{O}_{1 \mathrm{~s}}$ spectra of the various samples. Deconvoluted XPS peaks attributable to oxgyen-contaning functiontalities, including $\mathrm{C}-\mathrm{O}, \mathrm{C}=\mathrm{O}$, and $\mathrm{OH}$, can be noted. Figure $3 \mathrm{~d}$ shows a TEM image of A-CNS50C4h as a representative activated sample, which verifies the well retained nanosphere morphology.

To investigate the effects of nitric acid activation on the surface wetting properties by different electrolytes, the contact angles of the different carbons towards three aqueous solutions (DI water, $2 \mathrm{M} \mathrm{KOH}$, and $1 \mathrm{M} \mathrm{H}_{2} \mathrm{SO}_{4}$ ) were measured (see Table 1; Figure 3e). Such surface wetting properties revealed by contact angle data should affect supercapacitive properties of these carbon materials. ${ }^{[24]}$ Due to the enhanced content of hydrophilic oxygen-containing surface functionalities, the surface wetting properties of the activated samples show significant improvement towards water and $2 \mathrm{M} \mathrm{KOH}$ solution. The contact angles of $\mathrm{DI}$ water and $2 \mathrm{M} \mathrm{KOH}$ solution on the thin films of the activated carbon samples all show a clear trend of decrease with the increase of activation temperature. The unactivated CNS shows contact angles of $134^{\circ}$ and $119^{\circ}$ for DI water and $2 \mathrm{M} \mathrm{KOH}$ solution, respectively. Upon nitric acid activation, the water contact angles for A-CNS25C4h, $\mathrm{A}-\mathrm{CNS} 50 \mathrm{C} 4 \mathrm{~h}$, and A-CNS80C4h are $133^{\circ}, 118^{\circ}$, and $102^{\circ}$, respectively; the corresponding values for $2 \mathrm{M} \mathrm{KOH}$ solution are $119^{\circ}, 109^{\circ}$, and $97^{\circ}$, respectively. These indicate the enhanced surface wetness of the carbon material by DI water and $2 \mathrm{M} \mathrm{KOH}$ solution following nitric acid activation, which should be beneficial to the improvement in supercapacitive properties in $2 \mathrm{M} \mathrm{KOH}$ electrolyte due to the improved infiltration of the electrolytes into the pores for better wetting. On the contrary, relative to the value of $116^{\circ}$ for the unactivated CNS, the contact angle for $1 \mathrm{M} \mathrm{H}_{2} \mathrm{SO}_{4}$ solution shows an opposite trend of change $\left(116,114\right.$, and $125^{\circ}$, respectively) with instead a slight increase upon the increase of activation temperature, suggestive of the deterioration in surface wetting by $1 \mathrm{M} \mathrm{H}_{2} \mathrm{SO}_{4}$ solution upon activation. This leads to our expectation of their deteriorated supercapacitive properties in $1 \mathrm{M} \mathrm{H}_{2} \mathrm{SO}_{4}$ electrolyte upon the enhanced surface activation at the elevated temperature. These contact angle data also indicate that the surface acidity on the activated carbon materials affects the surface wetting properties of the carbon materials, with enhanced wetting noted with the basic $2 \mathrm{M} \mathrm{KOH}$ solution and deteriorated wetting with the acidic $1 \mathrm{M} \mathrm{H}_{2} \mathrm{SO}_{4}$ solution.

\section{Supercapacitive performance of activated CNS in $2 \mathrm{M}$ $\mathrm{KOH}$ electrolyte}

The supercapacitive properties of the A-CNS samples were firstly evaluated in a 3-electrode cell with $2 \mathrm{M} \mathrm{KOH}$ as the aqueous electrolyte by CV, GCD, and EIS measurements. The working electrodes were prepared by loading the carbon samples on nickel foam. The measurements were all undertaken within a voltage range of -1.0 to $0 \mathrm{~V}$ ( $v s$. SCE).

Figure 4 a shows the CV curves of all activated samples and unactivated between -1.0 and $0 \mathrm{~V}$ ( $v s$. SCE) at the scan rate of $10 \mathrm{mV} \cdot \mathrm{s}^{-1}$. Figure $4 \mathrm{c}$ shows the CV curves of A-CNS80C4h at different scan rates from 10 to $200 \mathrm{mV} \cdot \mathrm{s}^{-1}$. While the unactivated CNS shows a quasi-rectangular curve (see Figure 4a), the activated samples generally show weak but broad redox peaks absent in the unactivated CNS, which should result from the redox reactions of the oxygen-containing functionalities on the surface of the activated carbon materials. The specific capacitance data calculated from the CV curves are listed in Table 2. At $10 \mathrm{mV} / \mathrm{s}$, it increases by following the order: CNS $\left(71 \mathrm{~F} \cdot \mathrm{g}^{-1}\right)<\mathrm{A}-\mathrm{CNS} 25 \mathrm{C} 2 \mathrm{~h}\left(118 \mathrm{~F} \cdot \mathrm{g}^{-1}\right) \approx \mathrm{A}-\mathrm{CNS} 25 \mathrm{C} 4 \mathrm{~h}(118$ $\left.\mathrm{F} \cdot \mathrm{g}^{-1}\right)<\mathrm{A}-\mathrm{CNS} 50 \mathrm{C} 2 \mathrm{~h}\left(131 \mathrm{~F} \cdot \mathrm{g}^{-1}\right)<\mathrm{A}-\mathrm{CNS} 50 \mathrm{C} 4 \mathrm{~h}\left(141 \mathrm{~F} \cdot \mathrm{g}^{-1}\right) \approx$ 

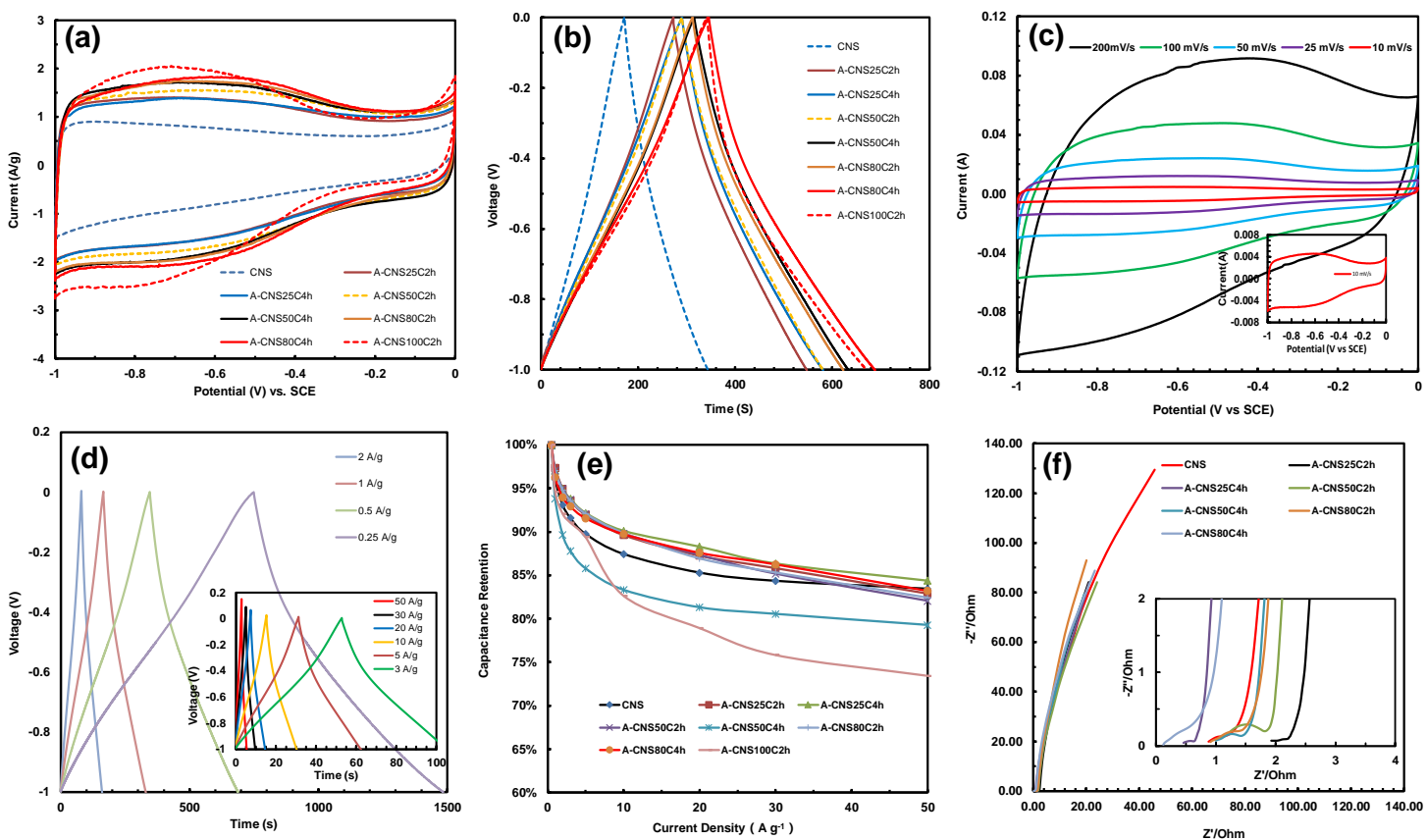

Figure 4 (a) CV curves (at $10 \mathrm{mV} \mathrm{s}^{-1}$ ) and (b) GCD curves (at $0.5 \mathrm{~A} \mathrm{~g}^{-1}$ ) of the various carbon samples; (c) CV curves at various scannnig rates and (d) GCD curves at various current densities of $A-C N S 80 C 4 h$; (e) captacitance retention (relative to $0.5 \mathrm{~A} \cdot \mathrm{g}^{-1}$ ) of various samples at different current densities; (f) Nyquist plots of various samples. All measurements were undertaken in a 3-electrode cell in $2 \mathrm{M} \mathrm{KOH}$.

A-CNS80C2h $\left(140 \mathrm{~F} \cdot \mathrm{g}^{-1}\right)<\mathrm{A}-\mathrm{CNS} 100 \mathrm{C} 2 \mathrm{~h}\left(144 \mathrm{~F} \cdot \mathrm{g}^{-1}\right) \approx$ A-CNS80C4h $\left(144 \mathrm{~F} \cdot \mathrm{g}^{-1}\right)$. This order follows very well the decrease in contact angle, or the increased surface wetness, for 2 $\mathrm{M} \mathrm{KOH}$ solution observed above upon nitric acid activation. It indicates the direct correlation between electrolyte contact angle/surface wetting and the specific capacitance. Among all carbon samples, AC-NA80C4h appears to have the highest specific capacitance at all CV scanning rates. All the activated samples, except that collapsed at $100^{\circ} \mathrm{C}$, thus have significantly enhanced specific capacitance relative to unactivated CNS of hydrophobic surface, showing the positive effects of the activation given the modification of the surface properties of the carbon materials due to the enhanced content of the surface functionalities for pseudocapacitance and improved surface wetting.

A similar trend of change is observed at other scan rates. This trend of change reflects the effects of activation temperature and time on the specific capacitance. At a given activation time ( 2 or $4 \mathrm{~h}$ ), the increase of activation temperature from 25 to $80 \stackrel{\circ}{\circ}$ leads to consistent, appreciable increases in the specific capacitance; however, a further increase from 80 to $100 \stackrel{\circ}{\circ}$ leads to a slight decrease in specific capacitance possibly due to the collapse of some pore structure at the harsh condition of $100{ }^{\circ} \mathrm{C}$. At the lowest temperature of $25^{\circ} \mathrm{C}$, extending the activation time from 2 to $4 \mathrm{~h}$ has negligible effects on the specific capacitance due to the low reactivity at this temperature. At the highest temperature of $100^{\circ} \mathrm{C}$, extending the time from 2 to $4 \mathrm{~h}$ leads to complete collapse of pore structures. At any intermediate temperature (50 or $80{ }^{\circ} \mathrm{C}$ ), increasing the activation time leads to appreciably enhanced specific capacitance. In particular, the combination of $80{ }^{\circ} \mathrm{C}$ and $4 \mathrm{~h}$ appears to be the optimum activation condition given the highest specific capacitance of A-CNS80C4h among all samples in all the CV measurements.

The GCD curves of the various carbon samples obtained at the current density of $0.5 \mathrm{~A} \cdot \mathrm{g}^{-1}$ are shown in Figure $4 \mathrm{~b}$. The GCD curves at different current densities for the representative carbon, A-CNS80C4h, are shown in Figure 4d. Table 2 summarizes the specific capacitance results calculated from the GCD measurements at different current densities from 0.5 to 50 $A \cdot g^{-1}$. The GCD curves are generally triangle-like and show a strong dependence of discharge time on current density. The voltage drop resulting from equivalent series resistance (ESR) is favorably very small (even at high current density of 30 and $50 \mathrm{~A} \cdot \mathrm{g}^{-1}$, see the inset in Figure $4 \mathrm{~d}$ ), which is also confirmed with EIS results to be shown below.

A similar order of change, as above from CV measurements, is found with the specific capacitance data obtained from GCD measurements among the samples, with A-CNS80C4h showing the best specific capacitance nearly at all current densities (e.g., $172 \mathrm{~F} \cdot \mathrm{g}^{-1}$ at $0.5 \mathrm{~A} \cdot \mathrm{g}^{-1}$ ). Similar to an earlier study by Lang et al., ${ }^{[9]}$ even though the specific surface area and pore volume decrease slightly after nitric acid activation, the specific capacitance increase markedly in $2 \mathrm{M} \mathrm{KOH}$ electrolyte after concentrated nitric acid activation. This increase should result in part from the pseudocapacitive effects of the surface functional groups following the strong oxidization with the concentrated nitric acid. Meanwhile, the enhanced surface hydrophilicity upon nitric acid activation may also help the diffusion of the electrolyte and thus contribute to the enhanced specific capacitance.

Figure $4 \mathrm{e}$ shows the capacitance retention (relative to the corresponding values at $0.5 \mathrm{~A} \cdot \mathrm{g}^{-1}$ ) at different current densities for the carbon samples. All carbon samples have the extremely high capacitance retention of about $90 \%$ and $83 \%$ at the high current density of 10 and $50 \mathrm{~A} \cdot \mathrm{g}^{-1}$, respectively, except A-CNS100C2h with relatively lower retention values of $83 \%$ and $73 \%$, respectively. The rate performance found here with these samples are even superior to many high-rate carbonbased electrode materials reported in the literature. In an earlier study by our group, ${ }^{[21]}$ activated carbon microparticles without hierarchical pore structures obtained from homopolymer of DEB by $\mathrm{KOH}$ activation has a much lower capacitance retention of only $56 \%$ at $10 \mathrm{~A} \cdot \mathrm{g}^{-1}$, where the carbon samples contain 
Table 2 Specific capacitance data (in $\mathrm{F} \cdot \mathrm{g}^{-1}$ ) of various carbon samples obtained from $\mathrm{CV}$ and GCD measurements in 3-electrodel cell in $2 \mathrm{M} \mathrm{KOH}$

\begin{tabular}{|c|c|c|c|c|c|c|c|c|c|}
\hline \multicolumn{2}{|c|}{$\begin{array}{c}\text { Scanning rate } \\
\left(\mathrm{mV} \cdot \mathrm{s}^{-1}\right) \\
\text { or current density } \\
\left(\mathrm{A} \cdot \mathrm{g}^{-1}\right) \\
\end{array}$} & CNS & A-CNS25C2h & A-CNS25C4h & \multicolumn{5}{|c|}{ A-CNS50C2h A-CNS50C4hA-CNS80C2h A-CNS80C4h A-CNS100C2h } \\
\hline \multirow{5}{*}{ CV } & 200 & 62 & 98 & 99 & 99 & 105 & 101 & 130 & 110 \\
\hline & 100 & 68 & 112 & 110 & 116 & 124 & 122 & 145 & 129 \\
\hline & 50 & 72 & 120 & 116 & 125 & 135 & 134 & 152 & 142 \\
\hline & 25 & 73 & 123 & 119 & 131 & 141 & 140 & 152 & 147 \\
\hline & 10 & 71 & 118 & 118 & 131 & 141 & 140 & 144 & 144 \\
\hline \multirow{9}{*}{ GCD } & 0.5 & 86 & 140 & 146 & 146 & 159 & 156 & 172 & 165 \\
\hline & 1 & 83 & 136 & 137 & 142 & 154 & 151 & 165 & 156 \\
\hline & 2 & 80 & 133 & 131 & 139 & 151 & 148 & 161 & 152 \\
\hline & 3 & 79 & 131 & 128 & 137 & 149 & 146 & 159 & 150 \\
\hline & 5 & 77 & 128 & 125 & 135 & 147 & 143 & 157 & 148 \\
\hline & 10 & 75 & 125 & 121 & 132 & 143 & 140 & 154 & 136 \\
\hline & 20 & 74 & 122 & 118 & 129 & 139 & 135 & 150 & 130 \\
\hline & 30 & 73 & 120 & 117 & 126 & 136 & 133 & 148 & 125 \\
\hline & 50 & 72 & 116 & 116 & 123 & 131 & 128 & 143 & 121 \\
\hline
\end{tabular}

primarily micropores. As Zhu et al. mentioned, the quick decrease of specific capacitance at high current density is caused by insufficient ion transport and/or the relatively insufficient faradic redox reaction of the carbon samples under higher discharge current densities. ${ }^{[8]}$ For the carbon nanosphere samples herein with abundant large mesopores and macropores, fast transport of ions can be facilitated to render advantageously high capacitance retention at high currents.

Figure $4 \mathrm{f}$ shows the Nyquist plots of activated and unactivated samples, obtained from EIS measurements within the frequency range of $10 \mathrm{kHz}$ to $0.01 \mathrm{~Hz}$. Typical of electrical double layer capacitors (EDLCs), all carbon samples show a semicircle at high frequency and a nearly vertical line at low frequency. ${ }^{[25]}$ The expanded semicircle in the high frequency region is given in the inset. Equivalent serial resistance (ESR) can be calculated from the intercept of the semicircle at real axis $(Z)$, which is affected by ionic resistance of the electrolyte, internal resistance of the carbon materials and current collector, and contact resistance at the carbon material/current collector interface. Low ESR values in the range of $0.1-1.9 \Omega$ are found with unactivated and nitric acid activated carbons, which are also reflected in the low voltage drop in the GCD curves as mentioned earlier (see Figure 4d). At the low frequencies, the Warburg-type line (with a slope of $45^{\circ}$ ) is not obvious, indicating that ion transfer within micropores occur fast in these carbons due to short micropore length and abundant mesopores/ macropores. ${ }^{[19]}$

Based on the supercapacitive results obtained from 3-electrode cell, we have subsequently fabricated a symmetric 2-electrode cell using A-CNS80C4h as the electrode material since it shows the highest specific capacitance in 3-electrode cell configuration. Electrochemical measurements were undertaken in aqueous $2 \mathrm{M} \mathrm{KOH}$ electrolyte within the voltage window of $0-1 \mathrm{~V}$. Unlike those measured in 3-electrode cell, the CV curves of the 2-electrode cell at different scan rates (Figure $5 a)$ are nearly rectangular with a specific capacitance of 121 $\mathrm{F} \cdot \mathrm{g}^{-1}$ at $10 \mathrm{mV} \cdot \mathrm{s}^{-1}$. The GCD curves in Figure $5 \mathrm{~b}$ exhibit a triangle-like shape and the voltage drop resulting from discharge is very small even at the highest current density of $50 \mathrm{~A} \cdot \mathrm{g}^{-1}$. The specific capacitance data calculated from GCD curves are $158,139,119,115$, and $98 \mathrm{~F} \cdot \mathrm{g}^{-1}$ at $0.1,0.5,5,10$, and $50 \mathrm{~A} \cdot \mathrm{g}^{-1}$, respectively (Figure $5 \mathrm{c}$ ). The capacitance retention at 10 and $50 \mathrm{~A} \cdot \mathrm{g}^{-1}$ is $73 \%$ and $62 \%$, respectively, relative to the value at $0.1 \mathrm{~A} \cdot \mathrm{g}^{-1}$. These percentages of capacitance retention are high, relative to a retention of $52 \%$ at $10 \mathrm{~A} \cdot \mathrm{g}^{-1}$ reported by our group for a 2-electrode cell fabricated with $\mathrm{KOH}$-activated carbon microparticles obtained from homopolymer of DEB. ${ }^{[21]}$ Relative to those obtained from GCD measurements in a 3-electrode cell at identical current densities, the capacitance values measured in 2-electrode cell are lower due to the heightened sensitivity of 3 -electrode cell. ${ }^{[26]}$ Figure $5 d$ shows the Nyquist plot of the 2-electrode cell with an ESR of $0.56 \Omega$. This ESR value is nearly twice of that $(0.34 \Omega)$ in 3-electrode cell. Figure 5 e shows the cyclic stability of the 2-electrode cell over 2500 GCD cycles at $5 \mathrm{~A} \cdot \mathrm{g}^{-1}$. The specific capacitance is very stable with $91 \%$ of retention after 2500 cycles, demonstrating the excellent stability of the 2-electrode cell built with the activated carbon nanosphere sample.

\section{Supercapacitive performance of activated CNS in $1 \mathrm{M}$ $\mathrm{H}_{2} \mathrm{SO}_{4}$ electrolyte}

The supercapacitive properties of nitric acid activated CNS samples were further evaluated in $1 \mathrm{M} \mathrm{H}_{2} \mathrm{SO}_{4}$ electrolyte in a 3 -electrode cell. Electrodes were prepared by loading the carbons on $\mathrm{Ti}$ foil. Given the use of acidic electrolyte, the CV and GCD measurements were performed within the voltage range of -0.2 to $0.8 \mathrm{~V}$ ( $v s$. SCE).

Figure 6 a shows the $\mathrm{CV}$ curves of the electrodes made with the various carbons at the scan rate of $10 \mathrm{mV} \cdot \mathrm{s}^{-1}$. Figure $6 \mathrm{c}$ shows the CV curves for A-CNS25C2h as a representative activated carbon at various scan rates. The CV curve of the unactivated CNS has a nearly perfect rectangular shape at 10 $\mathrm{mV} \cdot \mathrm{s}^{-1}$, suggesting its absence of significant surface functionalities. All the activated samples show redox peaks centered at around 0.3 (anodic mode) and $0.2 \mathrm{~V}$ (cathodic mode), respectively. Arising from redox reactions of the oxygen-containing carbonlyl functiontalities, these peaks contribute to Faradic pseudocapacitance. ${ }^{[12]}$ Table 3 lists the specific capacitance data calculated from the CV measurements. Though the activated carbons generally show enhanced specific capacitance than the unactivated one due to the pseudocapacitance resulting from the surface functionality, a very different trend of change is observed with the respect to the effects of activation temperature and time on the capacitance value in the acidic electrolyte relative to that in basic electrolyte. In $1 \mathrm{M} \mathrm{H}_{2} \mathrm{SO}_{4}$ electrolyte, the specific capacitance at each scan rate increases by following the general order: CNS $\approx A-C N S 100 C 2 h<$ $\mathrm{A}-\mathrm{CNS} 80 \mathrm{C} 4 \mathrm{~h}<\mathrm{A}-\mathrm{CNS} 80 \mathrm{C} 2 \mathrm{~h}<\mathrm{A}-\mathrm{CNS} 50 \mathrm{C} 2 \mathrm{~h} \approx \mathrm{A}-\mathrm{CNS} 50 \mathrm{C} 4 \mathrm{~h}$ 

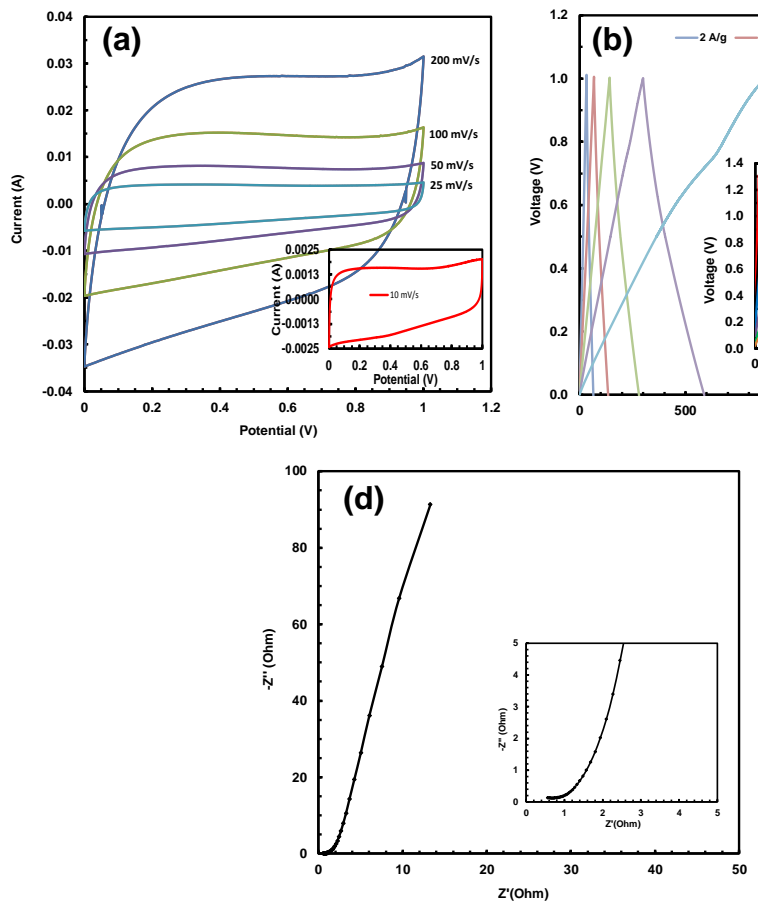
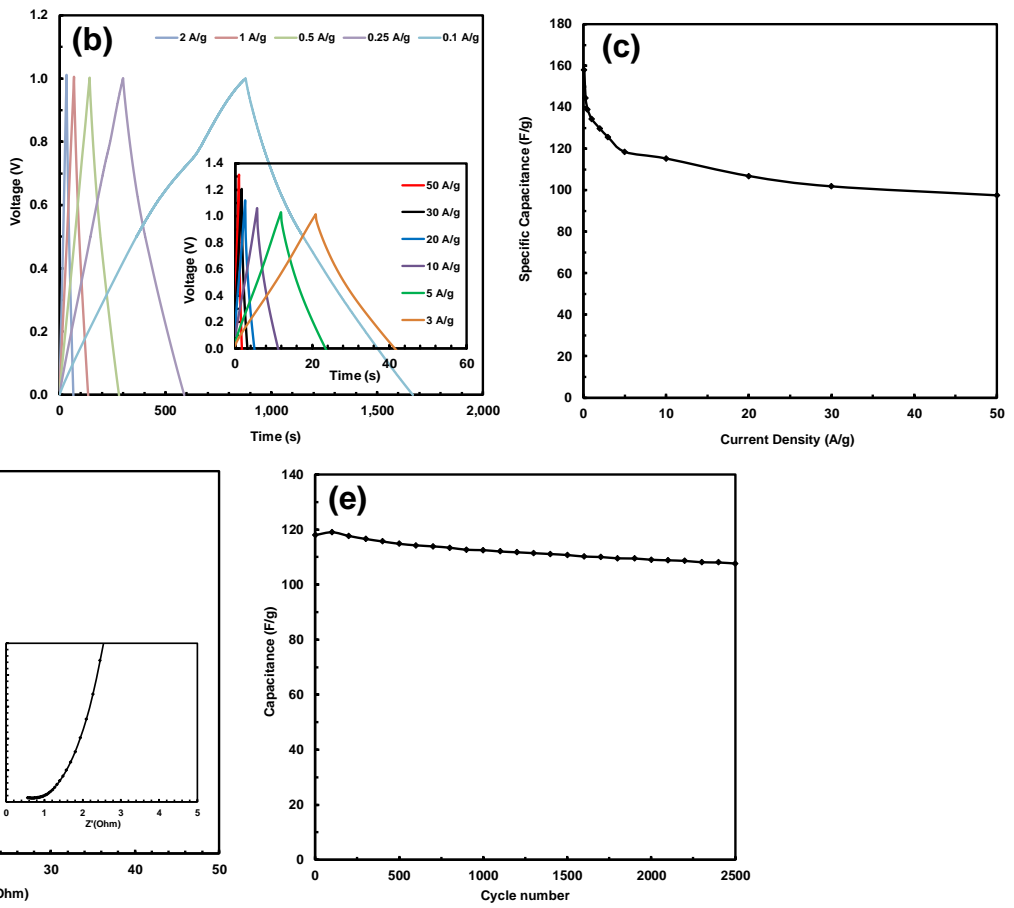

Figure 5 (a) CV curves at various scanning rates and (b) GCD curves at various current densities of a two-electrode cell fabricated with A-CNS80C4h in $2 \mathrm{M} \mathrm{KOH}$; (c) plot of specific capacitance as a function of current density obtained from the GCD data; (d) Nyquist plot of the two-electrode cell; (e) cyclic stability of the two-electrode cell at $5 \mathrm{~A} \cdot \mathrm{g}^{-1}$ over $2500 \mathrm{GCD}$ cycles.
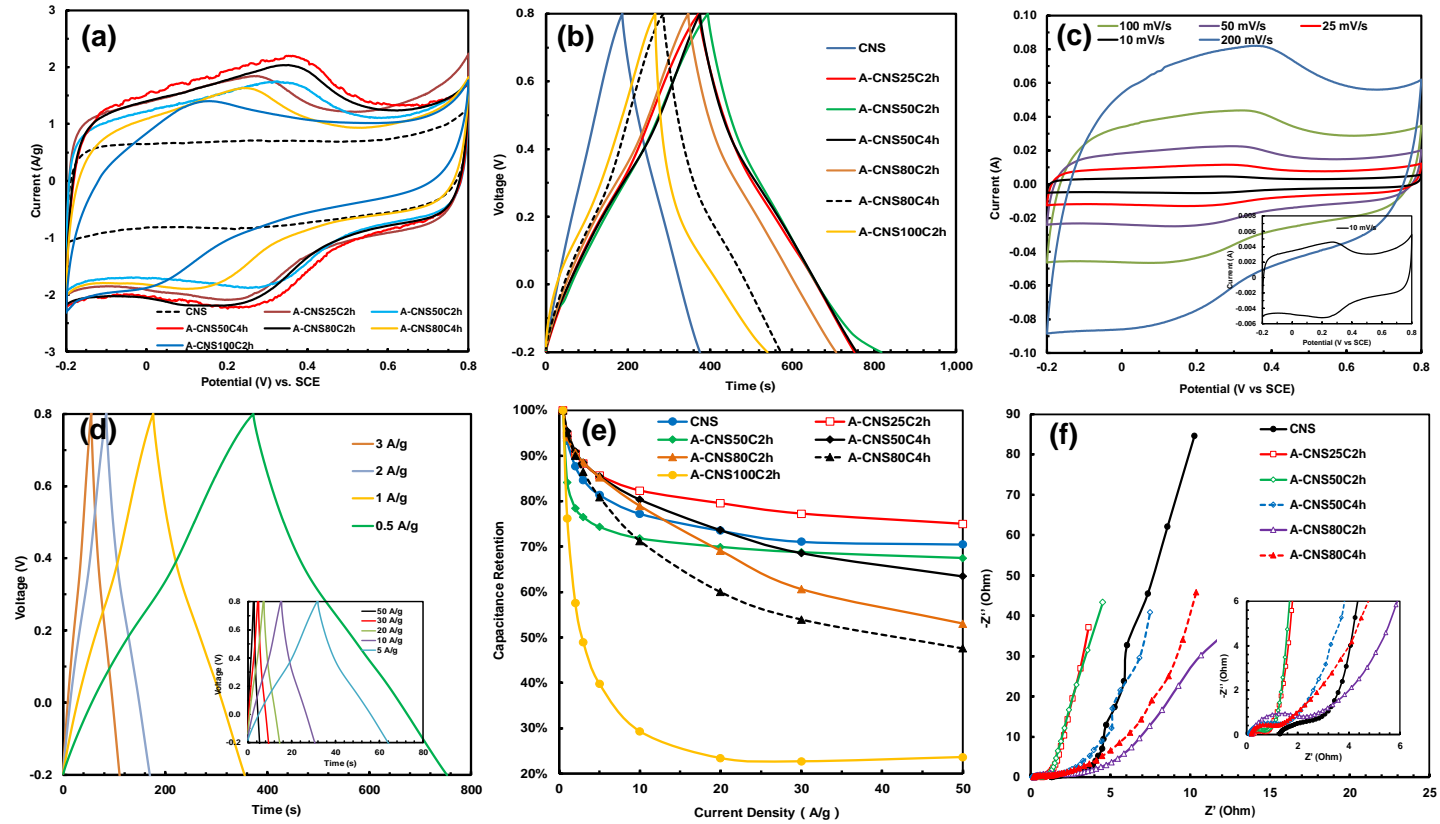

Figure 6 (a) CV curves (at $10 \mathrm{mV} \cdot \mathrm{s}^{-1}$ ) and (b) GCD curves (at $0.5 \mathrm{~A} \cdot \mathrm{g}^{-1}$ ) of various carbon samples; (c) CV curves at various scannnig rates and (d) GCD curves at various current densities of A-CNS25C2h; (e) captacitance retention (relative to $0.5 \mathrm{~A} \cdot \mathrm{g}^{-1}$ ) of various samples at different current densities; (f) Nyquist plots of various samples. All measurements were undertaken in a 3-electrode cell in $1 \mathrm{M} \mathrm{H}_{2} \mathrm{SO}_{4}$.

$\approx \mathrm{A}-\mathrm{CNS} 25 \mathrm{C} 2 \mathrm{~h}$. While the differences in specific capacitance are only marginal and indistinct for those activated at 25 and 50 ${ }^{\circ} \mathrm{C}$, appreciably lower specific capacitance data are observed with those more heavily activated at 80 and $100{ }^{\circ} \mathrm{C}$. From this trend, it appears that enhanced activation at $80 / 100{ }^{\circ} \mathrm{C}$ or extending the activation time reduces the specific capacitance of the activated carbon. This differs dramatically from the results found in $2 \mathrm{M} \mathrm{KOH}$ electrolyte, indicating that the electrolyte plays an important role depending on the acidic or basic surface of the carbon materials. The trend of change is also in good agreement with the deteriorated surface wetting or enhanced contact angle data for $1 \mathrm{M} \mathrm{H}_{2} \mathrm{SO}_{4}$ solution. This indicates the dramatic effect of surface properties on the supercapacitive performance. 
Table 3 Specific capacitance data (in F. $\mathrm{g}^{-1}$ ) of various carbon samples obtained from CV and GCD measurements in a 3-electrodel cell in $1 \mathrm{M} \mathrm{H}_{2} \mathrm{SO}_{4}$

\begin{tabular}{|c|c|c|c|c|c|c|c|c|}
\hline \multicolumn{2}{|c|}{$\begin{array}{l}\text { Scanning rate/ } \\
\left(\mathrm{mV} \cdot \mathrm{s}^{-1}\right) \text { or current } \\
\text { density } /\left(\mathrm{A} \cdot \mathrm{g}^{-1}\right)\end{array}$} & \multirow{2}{*}{$\begin{array}{r}\text { CNS } \\
39\end{array}$} & \multirow{2}{*}{$\begin{array}{c}\text { A-CNS25C2h } \\
114\end{array}$} & \multirow{2}{*}{$\begin{array}{c}\text { A-CNS50C2h } \\
116\end{array}$} & \multirow{2}{*}{$\begin{array}{c}\text { A-CNS50C4h } \\
88\end{array}$} & \multirow{2}{*}{$\begin{array}{c}\text { A-CNS80C2h } \\
60\end{array}$} & \multirow{2}{*}{$\begin{array}{c}\text { A-CNS80C4h } \\
62\end{array}$} & \multirow{2}{*}{$\begin{array}{c}\text { A-CNS100C2h } \\
38\end{array}$} \\
\hline \multirow{5}{*}{ CV } & 200 & & & & & & & \\
\hline & 100 & 48 & 129 & 127 & 116 & 88 & 78 & 48 \\
\hline & 50 & 55 & 139 & 133 & 136 & 116 & 93 & 61 \\
\hline & 25 & 63 & 145 & 137 & 149 & 137 & 105 & 75 \\
\hline & 10 & 70 & 145 & 133 & 157 & 149 & 114 & 93 \\
\hline \multirow{9}{*}{ GCD } & 0.5 & 95 & 190 & 212 & 192 & 182 & 145 & 140 \\
\hline & 1 & 89 & 180 & 179 & 183 & 171 & 137 & 107 \\
\hline & 2 & 84 & 172 & 166 & 175 & 165 & 130 & 81 \\
\hline & 3 & 81 & 168 & 162 & 170 & 161 & 125 & 69 \\
\hline & 5 & 78 & 163 & 158 & 164 & 155 & 117 & 56 \\
\hline & 10 & 74 & 157 & 152 & 154 & 143 & 103 & 41 \\
\hline & 20 & 70 & 151 & 148 & 141 & 125 & 87 & 33 \\
\hline & 30 & 68 & 147 & 146 & 132 & 110 & 78 & 32 \\
\hline & 50 & 67 & 143 & 143 & 122 & 96 & 69 & 33 \\
\hline
\end{tabular}

Figure $6 b$ shows the GCD curves of the various carbons measured at $0.5 \mathrm{~A} \cdot \mathrm{g}^{-1}$; Figure $6 \mathrm{~d}$ shows, in particular, the GCD curves of AC-NA25C2h as a representative one in $1 \mathrm{M} \mathrm{H}_{2} \mathrm{SO}_{4}$ electrolyte at different current densities. The voltage drop resulting from equivalent series resistance (ESR) is also very small in $1 \mathrm{M} \mathrm{H}_{2} \mathrm{SO}_{4}$ electrolyte even at high current densities like $50 \mathrm{~A} \cdot \mathrm{g}^{-1}$. Consistent with those observed in CV curves, some plateaus corresponding to redox reactions of the surface functional groups can be seen at correspondingly similar voltages in the charge and discharge curves. The specific capacitance data calculated from the discharge curves in GCD measurements are also summarized in Table 3. A similar order of the specific capacitance as that derived from CV data can be found among the various samples.

Figure 6 e shows the percentage of capacitance retention at different current densities in reference to the values at $0.5 \mathrm{~A} \cdot \mathrm{g}^{-1}$. In general, the capacitance retention in $1 \mathrm{M} \mathrm{H}_{2} \mathrm{SO}_{4}$ electrolyte is not as good as the corresponding one in $2 \mathrm{M} \mathrm{KOH}$ electrolyte. The best retention is found with A-CNS25C2h, which has about $80 \%$ of capacitance retention at $50 \mathrm{~A} \cdot \mathrm{g}^{-1}$, along with the unactivated CNS being the second (ca. $72 \%$ retention). Generally, with the increase of activation temperature or time, a deterioration in the capacitance retention can be observed. In particular, A-CNS100C2h has the poorest capacitance retention of only $23 \%$. This is again in agreement with the deteriorated surface wetting by the $1 \mathrm{M} \mathrm{H}_{2} \mathrm{SO}_{4}$ solution noted above from the contact angle data.

Figure $6 f$ shows the Nyquist plots of the various carbons, obtained from EIS measurements in $1 \mathrm{M} \mathrm{H}_{2} \mathrm{SO}_{4}$. Again, all the carbons show the distinct parts associated with EDLCs in the plots. Similar to those in $2 \mathrm{M} \mathrm{KOH}$, low ESR values in the range of $0.1-0.3 \Omega$ are generally found with all the activated carbons. One distinct difference is noted in the intermediate frequency range. For the unactivated and weakly activated samples (CNS, A-CNS25C2h, A-CNS50C2h, A-CNS50C4h), the Warburg line (with a slope of about $45^{\circ}$ ) in the intermediate frequency range is nearly absent with a semicycle in the high frequency followed directly with a nearly vertical line at low frequency, while a long Warburg line is observed with the other samples that are more strongly activated at $80^{\circ} \mathrm{C}(\mathrm{A}-\mathrm{CNS} 80 \mathrm{C} 2 \mathrm{~h}$ and A-CNS80C4h). The Warburg line is ascribed to the ion movement within the micropores; a longer Warburg line corresponds to more ion diffusion resistance within the micropores. ${ }^{[27]}$ Clearly, a higher level of nitric acid activation reduces the wettability of the micropore surface toward the $1 \mathrm{M} \mathrm{H}_{2} \mathrm{SO}_{4}$ electrolyte, thus restricting the ion movement and in turn reducing the specific capacitance.

Besides the electrochemical results obtained from 3-electrode cell, a symmetric 2-electrode cell was also fabricated with A-CNS50C4h as the electrode material in $1 \mathrm{M} \mathrm{H}_{2} \mathrm{SO}_{4}$. Electrochemical measurements were conducted within the voltage window of $0-1 \mathrm{~V}$. Similar to the measurement of 2-electrode cell in $2 \mathrm{M} \mathrm{KOH}$, the CV curves of the 2-electrode cell at different scan rates (see Figure $7 \mathrm{a}$ ) are nearly rectangular, and the GCD curves in Figure $7 \mathrm{~b}$ exhibit a triangle-like shape and a very small voltage drop. The specific capacitance data calculated from GCD curves are 156, 128, 120,104, and $98 \mathrm{~F} \cdot \mathrm{g}^{-1}$ at $0.1,0.5,5,10$, and $50 \mathrm{~A} \cdot \mathrm{g}^{-1}$, respectively (Figure $7 \mathrm{c}$ ). The capacitance retention at 10 and $50 \mathrm{~A} \cdot \mathrm{g}^{-1}$ is $77 \%$ and $67 \%$, respectively, relative to the value at $0.1 \mathrm{~A} \cdot \mathrm{g}^{-1}$. Figure $7 \mathrm{~d}$ shows the Nyquist plot of the 2-electrode cell with an ESR of $0.18 \Omega$, which is also nearly twice of that $(0.10 \Omega)$ in the 3-electrode cell. From the cycling test, the capacitance retention is almost $100 \%$ after $2500 \mathrm{GCD}$ cycles at $5 \mathrm{~A} \cdot \mathrm{g}^{-1}$ though with an initial decay followed with a gradual recovery (see Figure 7e), demonstrating the excellent stability of the electrodes built with the nitric acid activated carbon in $1 \mathrm{M} \mathrm{H}_{2} \mathrm{SO}_{4}$.

\section{Conclusions}

The effects of nitric acid activation on the textural, surface, and supercapacitive properties of ultra-small carbon nanospheres (size: $24 \mathrm{~nm}$ ) synthesized by a catalytic emulsion polymerization strategy have been systematically investigated. In general, nitric acid activation shows marginal effects on the textural properties (surface area, pore volume, pore size distribution, etc.) of the carbon material within the activation temperature range of $25-80{ }^{\circ} \mathrm{C}$ and activation time up to $4 \mathrm{~h}$. However, at $100{ }^{\circ} \mathrm{C}$, a long activation for $4 \mathrm{~h}$ leads to the complete destruction of the carbon nanostructures. From the FTIR, XPS, and TGA characterizations, enhanced activation by increasing the temperature or extending the time leads to enhanced content of oxygen-containing surface functionalities. From contact angle measurements, enhanced activation leads to improved wetting of the surface of the carbon materials by DI water and $2 \mathrm{M} \mathrm{KOH}$ solution, but deteriorated surface wetting by $1 \mathrm{M} \mathrm{H}_{2} \mathrm{SO}_{4}$ solution. The activated carbon samples generally show improved specific capacitance compared to the unactivated CNS in both $2 \mathrm{M} \mathrm{KOH}$ and $1 \mathrm{M} \mathrm{H}_{2} \mathrm{SO}_{4}$ electrolytes due to the involvement of pseudocapacitance arising from the 

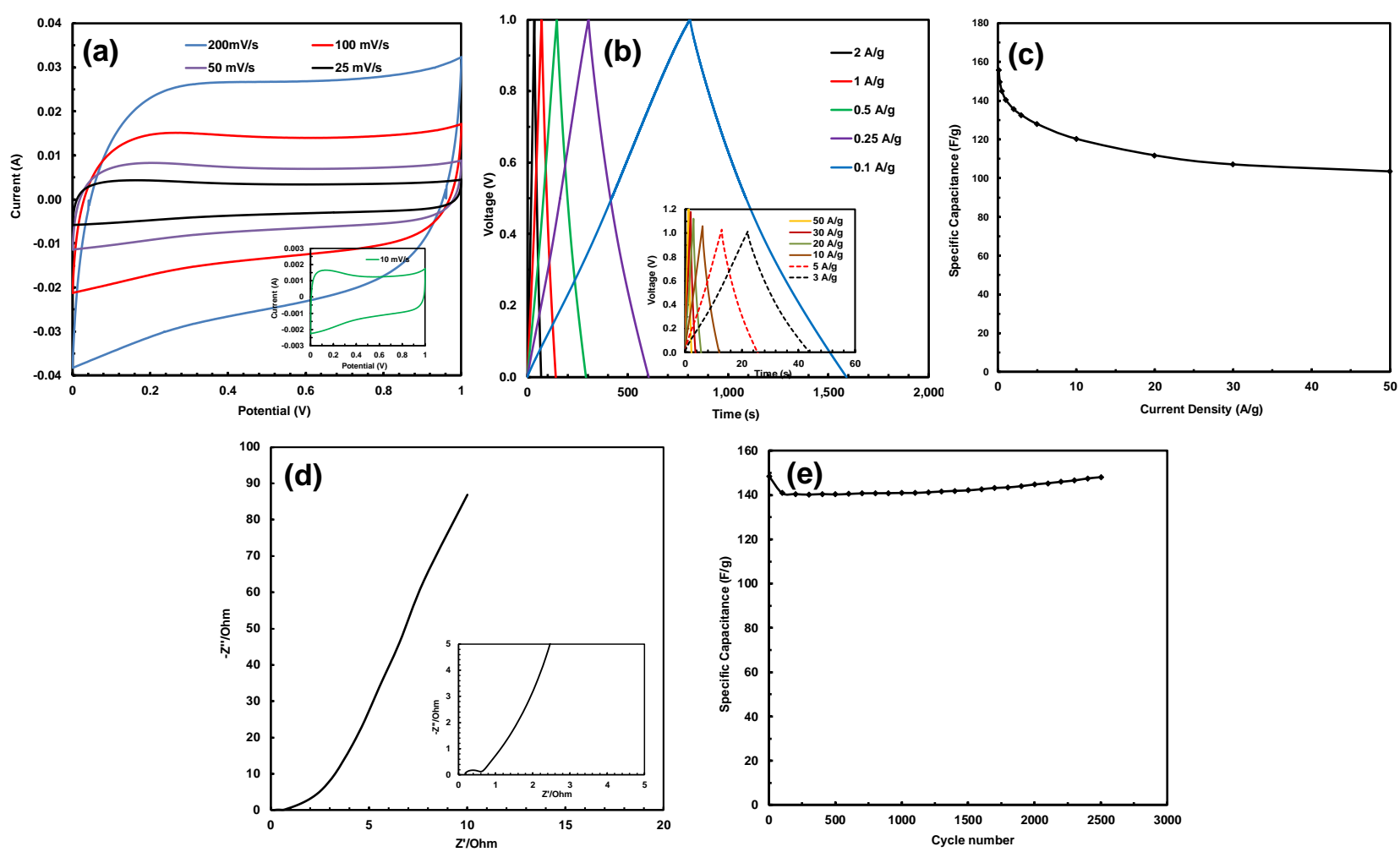

Figure 7 (a) CV curves at different scanning rates and (b) GCD curves at different current densities of the symmetrical 2-electrode cell with A-CNS50C4h in $1 \mathrm{M} \mathrm{H}_{2} \mathrm{SO}_{4}$; (c) plot of specific capacitance as a function of current density obtained from the GCD data; (d) Nyquist plot of the two-electrode cell; (e) cyclic stability of the two-electrode cell at $5 \mathrm{~A} \cdot \mathrm{g}^{-1}$ over $2500 \mathrm{GCD}$ cycles.

introduced surface functionalities following activation. In $2 \mathrm{M}$ $\mathrm{KOH}$ electrolyte, enhanced activation by increasing activation temperature and/or time leads to improved specific capacitance due to the increased supercapacitance and improved surface wetting by the electrolyte, with A-CNS80C4h showing the best supercapacitive performance (specific capacitance and rate performance). In $1 \mathrm{M} \mathrm{H}_{2} \mathrm{SO}_{4}$ electrolyte, enhanced activation leads instead to deteriorated supercapacitive performance (reduced specific capacitance and deteriorated rate performance), with A-CNS25C2h showing the most optimum performance, due to the deterioration in surface wetting by the acidic electrolyte. This difference highlights the distinct surface effect on the supercapacitive performance of carbon materials. Given their ultra-small nanosphere structures with short ion diffusion lengths, the optimum activated samples in both electrolytes are noted for their superior rate performance with excellent capacitance retention at high current densities (e.g., up to $83 \%$ at 50 $\mathrm{A} \cdot \mathrm{g}^{-1}$ relative to $0.5 \mathrm{~A} \cdot \mathrm{g}^{-1}$ in 3 -electrode cell).

\section{Acknowledgement}

The authors thank the funding support from the Canada Research Chair (CRC, Grant \#230723) and the Natural Science and Engineering Research Council (NSERC) of Canada (Grant \#477901-2015).

\section{References}

[1] (a) Simon, P.; Gogotsi, Y. Nat. Mater. 2008, 7, 845; (b) Lukatskaya, M. R.; Kota, S.; Lin, Z.; Zhao, M.-Q.; Shpigel, N.; Levi, M. D.; Halim, J.; Taberna, P.-L.; Barsoum, M. W.; Simon, P.; Gogotsi, Y. Nat. Energy 2017, 2, 17105.
[2] (a) Xia, K. S.; Gao, Q. M.; Jiang, J.H.; Hu, J. Carbon 2008, 46, 1718; (b) Li, H. F.; Xi, H. A.; Zhu, S. M.; Wen, Z. Y.; Wang, R. D. Microporous Mesoporous Mater. 2006, 96, 357; (c) Lang, J. W.; Yan, X. B.; Liu, W. W.; Wang, R. T.; Xue, Q. J. J. Power Sources 2012, 204, 220.

[3] Bazuła, P. A.; Lu, A. H.; Nitz, J. J.; Schüth, F. Microporous Mesoporous Mater. 2008, 108, 266.

[4] Wu, Z.; Webley, P. A.; Zhao, D. Langmuir 2010, 26, 10277.

[5] Han, Y.; Zhao, P. P.; Dong, X. T.; Zhang, C.; Liu, S. X. Front. Mater. Sci. 2014, 8, 391.

[6] Jiang, J.; Zhang, L.; Wang, X.; Holm, N.; Rajagopalan, K.; Chen, F.; Ma, S. Electrochim. Acta 2013, 113, 481.

[7] Venhryn, B. Y.; Stotsko, Z. A.; Grygorchak, I. I.; Bakhmatyuk, B. P.; Mudry, S. I. Ultrason. Sonochem. 2013, 20, 1302.

[8] Zhu, T.; Lu, Y.; Zheng, S.; Chen, Y.; Guo, H. Electrochim. Acta 2015, 152, 456.

[9] Lang, J. W.; Yan, X. B.; Liu, W. W.; Wang, R. T.; Xue, Q. J. J. Power Sources 2012, 204, 220.

[10] Lang, J. W.; Yan, X. B.; Yuan, X. Y.; Yang, J.; Xue, Q. J. J. Power Sources 2011, 196, 10472.

[11] Cai, T.; Zhou, M.; Ren, D.; Han, G.; Guan, S. J. Power Sources 2013, 231, 197.

[12] Fan, L. Z.; Qiao, S.; Song, W.; Wu, M.; He, X.; Qu, X. Electrochim. Acta 2013, 105, 299.

[13] Ren, T. Z.; Liu, L.; Zhang, Y.; Yuan, Z. Y. J. Solid State Electrochem. 2013, 17, 2223. 
[14] Wang, Y.; Tao, S.; An, Y. Microporous Mesoporous Mater. 2012, 163, 249

[15] Zhang, X.; Wang, X.; Jiang, L.; Wu, H.; Wu, C.; Su, J. J. Power Sources 2012, 216, 290.

[16] Yan, Y.; Kuila, T.; Kim, N. H.; Lee, J. H. Carbon 2014, 74, 195.

[17] Zheng, L.; Wang, Y.; Wang, X.; Wang, X.; An, H.; Yi, L. J Mater. Sci. 2010, 45, 6030 .

[18] Zheng, S.; Zhu, T.; Chen, Y.; Lin, C.; Chen, Y.; Guo, H. J. Nanopart. Res. 2014, 16, 1.

[19] Tiwari, V. K.; Chen, Z.; Gao, F.; Gu, Z.; Sun, X.; Ye, Z. J. Mater. Chem. A 2017, 5, 12131.

[20] Xia, K. S.; Gao, Q. M.; Jiang, J.H.; Hu, J. Carbon 2008, 46, 1718.

[21] Grundy, M.; Ye, Z. J. Mater. Chem. A 2014, 2, 20316.

[22] Dong, Z.; Ye, Z. Macromolecules 2012, 45, 5020.
[23] (a) Wang, D. W.; Li, F.; Liu, M.; Cheng, H. M. New Carbon Mater. 2007, 22, 307; (b) Yan, Y.; Kuila, T.; Kim, N. H.; Lee, J. H. Carbon 2014, 74, 195.

[24] Vadiyar, M. M.; Bhise, S. C.; Patil, S. K.; Kolekar, S. S.; Shelke, A. R.; Deshpande, N. G.; Chang, J.-Y.; Ghule, K. S.; Ghule, A. V. Chem. Commun. 2016, 52, 2557.

[25] Lang, J. W.; Yan, X. B.; Liu, W. W.; Wang, R. T.; Xue, Q. J. J. Power Sources 2012, 204, 220.

[26] Stoller, M. D.; Ruoff, R. S. Energy Environ. Sci. 2010, 3, 1294.

[27] Puthusseri, D.; Aravindan, V.; Madhavi, S.; Ogale, S. Energy Environ. Sci. 2004, 7, 728.

Received September 8, 2018 Accepted September 23, 2018 